\title{
In-vitro and in-vivo evaluation of Inorganic Salts for the Management of Wheat Stem Rust (Pucciniagraminis f.sp. trtici)
}

\author{
Yehizbalem Azmeraw ${ }^{1 *}$, Belayneh Admassu ${ }^{2}$, Bekele Abeyo ${ }^{3}$ and Netsanet Bacha ${ }^{4}$ \\ Date Received: $18^{\text {th }}$ September 2019 / Date Accepted: $10^{\text {th }}$ December 2019
}

\begin{abstract}
Purpose : The development of new resistant pathogen races is increasing the concern of food safety and the environments are driving new search for alternative disease management strategies. This study was conducted to evaluate the effect of inorganic salts on wheat stem rust under in-vitro and in-vivo conditions.

Research Method: Inorganic salts were evaluated on their effect on the percentage uredospore germination, pustule number and pustule length of Pucciniagraminisf.sp. tritici at different concentrations, in-vitro and invivo.All the data were subjected to analysis of variance using $S A S$ version 9.1.3 software. The least significant difference at $5 \%$ level of significance was used to separate treatment means.
\end{abstract}

Findings : There was a significant $(P<0.05)$ difference among inorganic salts and their concentrations on the germination of Pgturedospores, in-vitro. Potassium carbonate completely inhibited the germination of Pgturedospores (100\%) at all concentrations (i.e. 10, 15, and $20 \mathrm{gl}-1$ ) followed by potassium bicarbonate, sodium bicarbonate and ammonium bicarbonate with inhibitions of 99.7, 97.33 and 97\%, respectively. The lowest inhibition of spore germination was recorded from potassium dihydrogen phosphate (6.7\%) and potassium chloride (9.3\%) at $5 \mathrm{gl}-1$. The in-vivo study showed that six inorganic salts significantly $(P<0.05)$ reduced the number of pustules and pustule lengths on susceptible wheat cultivar 'McNair'.

Originality/Value : The present study identified potassium carbonate and potassium bicarbonate as the best inorganic salts to manage wheat stem rust.

Keywords: Inorganic salts, In-vitro, In-vivo, Pucciniagraminis f.sp. tritici, Wheat stem rust

\section{INTRODUCTION}

Wheat (Triticumspp.) is one of the most important cereal crops in the world in terms of production and nutritional value. In Ethiopia, it is an important staple food crop. It is the preferred diets of Ethiopians, providing about $15 \%$ of the caloric intake for over 90 million population (FAO, 2015), placing it second after maize and slightly ahead of teff, sorghum and enset, which contribute 10-12\% each (Minot et al., 2015). The area under wheat production is estimated to be around 1.7 million hectares (CSA, 2018), which makes the country the largest wheat producer (4.64 million tons) in Sub-Saharan Africa. However, productivity of wheat in Ethiopia is very low. The low productivity is attributed to several factors including biotic (diseases, insect pests and weeds), abiotic (moisture, soil fertility, etc) and lack or poor adoption of new agricultural technologies (Zegeye et al., 2001).

Among those biotic factors, stem rust caused by the fungus Pucciniagraminis f.sp.triticiEriks. and E. Henn, has been the most devastating wheat production problem. The disease is mostly severe at the later stage of crop development and is mainly a disease of vegetative and the reproductive portion of the host (Roelfs, 1985).

\footnotetext{
${ }^{*}$ Department of plant sciences, Debre Tabor University, P.O. Box 2260, Debre Tabor, Ethiopia.

yehizbalem2002@gmail.com

University of Idaho, Dept. of Entomology, Plant Pathology and Nematology, Aberdeen Research and Extension Center, $1693 \mathrm{~S}$ $2700 \mathrm{~W}$, Aberdeen ID 83210, USA

International Maize and Wheat Improvement Center, P.O. Box 5689, Addis Ababa, Ethiopia.

4 Ethiopian Institute of Agricultural Research, P.O. Box 2003, Addis Ababa, Ethiopia.

(D) ORCID http://orcid.org/0000-0002-4636-5318
} 
Under favorable environmental conditions, stem rust can cause yield losses of up to $100 \%$ in susceptible wheat varieties (Leonard and Szabo, 2005;Roelfs, 1985). In Ethiopia, yield losses due to stem rust have been reported to be in the range of $61-100 \%$ depending on the susceptibility of the variety and environmental conditions (Bechere et al., 2000).

Management practices such as host resistance, use of chemicals and cultural methods are implemented to control stem rust in Ethiopia. The use of synthetic pesticides remains the most widely used disease control measure against plant pathogens, even though they have shown major drawbacks such as their lack of long-term efficacy due to the development of resistance by plant pathogens (Avis, 2007). In addition, Kibria et al., (2010) and Komarek et al., (2010) reported that the regular use of fungicides can potentially pose a risk to the environment, particularly if residual effect in the soil migrate off site and enter waterways. For instance, concerns have been raised over the long term use of copper-based fungicides, which can result in the accumulation of copper in the soil. This in turn can have adverse effects on soil organisms and pose potential risks to the long term fertility of the soil (Komarek et al., 2010). Therefore, there is a need for finding alternative management options which are environmentally friendly, accessible and affordable to local farmers in the control of the disease. Several inorganic salts have been tested worldwide as alternative method to manage plant diseases on a wide range of crops. Foliar spray of sodium or potassium bicarbonates led to decreased powdery mildew (Leveillulataurica) severity in pepper plants (Fallik et al., 1997). Furthermore, septoria leaf blotch (Septoriatritici) of winter wheat was significantly reduced by foliar application of potassium chloride (Mann, 2004). The use of inorganic salts for disease management has advantages over application of synthetic fungicides because it is less costly, and non-poisonous to humans and the environment (Reuveni et al., 1995). Therefore, the present study was designed to evaluate the effect of inorganic salts on wheat stem rust (Pucciniagraminisf.sp. tritici) under in-vitroand in-vivo conditions.

\section{MATERIALS AND METHODS}

The present study consisted of two independent experiments i.e. in-vitroand in-vivo evaluation of inorganic salts on uredospore germination of $P g t$, and infection of wheat by $P g t$ under greenhouse conditions, respectively. The experiments were conducted at Ambo Agricultural Research Center.

\section{Effect of inorganic salts on uredospore germination of Pgt, in-vitro}

The inhibitory effect of inorganic salts on uredospore germination of Pucciniagraminis f.sp. tritici was evaluated using eight inorganic salts namely: potassium bicarbonate $\left(\mathrm{KHCO}_{3}\right)$, sodium bicarbonate $\left(\mathrm{NaHCO}_{3}\right)$, ammonium bicarbonate $\left(\mathrm{NH}_{4} \mathrm{HCO}_{3}\right)$, potassium carbonate $\left(\mathrm{K}_{2} \mathrm{CO}_{3}\right)$ dipotassium hydrogen phosphate $\left(\mathrm{K}_{2} \mathrm{HPO}_{4}\right)$, potassium dihydrogen phosphate $\left(\mathrm{KH}_{2} \mathrm{PO}_{4}\right)$, sodium chloride $(\mathrm{NaCl})$ and potassium chloride $(\mathrm{KCl})$ in in-vitro condition. A solution of each inorganic salt at concentrations of 5, 10, 15 and $20 \mathrm{gl}^{-1}$ was prepared. Five (5) milliliter of each solution was added on to a water agar medium in Petri dishes, and mixed gently to dispense uniformly. Pgt uredospore suspension adjusted at 100 spores $\mathrm{ml}^{-1}$ wasinoculated to the water agar medium having the various concentrations of inorganic salts. Water agar medium without any inorganic salts served as a control. All Petri dishes were later incubated in a chamber adjusted at $20 \pm 2$ ${ }^{\circ} \mathrm{C}$ and $95-100 \% \mathrm{RH}$ for $48 \mathrm{hrs}$. The experiment was set in a completely randomized design with three replications. The experiment was repeated following the same procedure.

\section{Foliar spray of inorganic salt on wheat stem rust infection}

The effect of inorganic salt foliar sprays on wheat stem rust infection was evaluated using the eight inorganic salts mentioned above. The experiment was conducted using the universally susceptible wheat variety 'McNair'. Five seeds of the variety 'McNair were grown in $8 \mathrm{~cm}$ diameter pots in the greenhouse. The inorganic salt solutions were applied at 5, 10, 15 and 20 $\mathrm{gl}^{-1}$ concentrations on the third leaves ( 21 days after planting) of each plant. Each 'McNair' 
plant received $30 \mathrm{ml}$ of the salt solution which was sprayed to cover the whole leaves ensuring both upper and lower surface of the leaves. Plants were kept at ambient temperature for one hour for the solution on the leaves to dry. An hour later, plants were inoculated with Pgt uredospore suspension adjusted at $1 \times 10^{5}$ spores $\mathrm{ml}^{-1}$. The spore suspension was applied using the spore inoculators 'Vacuubrand' (Wertheim, Germany). Inoculated plants were placed in a dew chamber at $18^{\circ} \mathrm{C}$ for $24 \mathrm{hrs}$ in the dark and $20^{\circ} \mathrm{C}$ in the light without the polyethylene cover. Water treated plants were used as control. Disease infection was assessed seven days after the application of inorganic salt solutions and inoculum of Pgt. The experiment was laid out in a completely randomized design with three replications and the experiment was repeated.

\section{Data collection}

The number of germinated and non-germinated uredospores on each agar medium was counted using compound microscope after $48 \mathrm{hrs}$ of inoculation. The percentage of germinated spores was calculated using the following formula.

Percentage of Uredospore germination $=\frac{\text { Number of germinated Uredospores }}{\text { Total number of innoculated Uredospores }} \times 100$

Additional disease data, such as the number of pustules and pustule lengths, from the in-vivo experiment were collected from seedlings. The number of pustules was counted at the middle of single leaves of randomly selected five plants. The shape of pustules was elliptical, hence the pustule length was measured by taking the length of five pustules from each plant per pot using graduated ruler. The average pustule length of the five measurements was used for the final analysis.

\section{Data analysis}

All the data, percent of uredospore germination, number of pustules and pustule length, were subjected to analysis of variance (ANOVA) using SAS version 9.1.3 software (SAS, 2003). The least significant difference (LSD) at 5\% level of significance was used to separate treatment means.

\section{RESULTS AND DISCUSSION}

\section{The effects of inorganic salts on uredospore germination}

There was a significant difference $(\mathrm{P}<0.05)$ among inorganic salts and their concentrations on the inhibition of uredospore germination of Puccinia gramisf.sp. tritici under in-vitro condition. Potassium carbonate showed the highest inhibition rate(100\%) of uredospore germination at all concentrations (Table 01 and Figure 01). Potassium bicarbonate was the second best with $99.7 \%$ inhibition rate, followed by sodium bicarbonate and ammonium bicarbonate with 97.3 and $97 \%$ at concentrations of $20 \mathrm{gl}^{-1}$ respectively. Potassium carbonate at all concentrations, sodium bicarbonate at 15 and $20 \mathrm{gl}^{-1}$, ammonium bicarbonate at 10,15 and 20 $\mathrm{gl}^{-1}$, potassium bicarbonate at 10,15 and $20 \mathrm{gl}^{-1}$, dipotassiumbiposphate at $20 \mathrm{gl}^{-1}$ inhibited spore germination by $95-100 \%$. The two compounds that were ineffective were potassium dihydrogen phosphate and sodium chloridewith spore inhibition rates ranging from $6.7-8.3$ and 14.7$37.3 \%$, respectively (Table 01 ).

Several studies showed that inorganic salts affect the germination of several plant pathogens. According to Turkkan et al., (2017) the germination of spores of Botrytis cinereawas completely inhibited by the use of potassium carbonate at 25 and $50 \mathrm{mM}$ and potassium bicarbonate at 50 and $75 \mathrm{mM}$. Theprevious studies have also shown that carbonate and bicarbonate salts including ammonium, sodium and potassium to have inhibitory effects on the mycelial growth of many fungal species (Droby et al., 2003;Latifa et al., 2011; Palou et al., 2001; Youssef et al., 2012). Similarly, Bombelli and Wright (2006) found that potassium bicarbonate reduced the mycelial growth of B.cinereato some extent $(65 \%)$ at $0.5 \%$; and had complete inhibitory effect at $1 \%$ and higher concentrations. 
Table 01: The effect of inorganic salts on in-vitro germination of uredospore of Pgt

\begin{tabular}{|c|c|c|}
\hline Inorganic salt & Concentration $\left(\mathrm{gl}^{-1}\right)$ & Germination (\%) \\
\hline \multirow{4}{*}{$\mathrm{NaHCO}_{3}$} & 5 & $51.7^{\mathrm{g}}$ \\
\hline & 10 & $12.0^{\text {ih }}$ \\
\hline & 15 & $4.3^{\mathrm{j}}$ \\
\hline & 20 & $2.7^{\mathrm{j}}$ \\
\hline \multirow{4}{*}{$\mathrm{NH}_{4} \mathrm{HCO}_{3}$} & 5 & $48.3^{\mathrm{g}}$ \\
\hline & 10 & $3.7^{\mathrm{j}}$ \\
\hline & 15 & $3.3^{\mathrm{j}}$ \\
\hline & 20 & $3.0^{\mathrm{j}}$ \\
\hline \multirow{4}{*}{$\mathrm{KCl}$} & 5 & $90.7^{\mathrm{bc}}$ \\
\hline & 10 & $76.7^{\mathrm{e}}$ \\
\hline & 15 & $68.3^{f}$ \\
\hline & 20 & $16.7^{\text {ih }}$ \\
\hline \multirow{4}{*}{$\mathrm{NaCl}$} & 5 & $85.3^{\mathrm{dc}}$ \\
\hline & 10 & $81.0 \mathrm{~d}^{\mathrm{e}}$ \\
\hline & 15 & $67.0^{\mathrm{f}}$ \\
\hline & 20 & $62.7^{\mathrm{f}}$ \\
\hline \multirow{4}{*}{$\mathrm{KHCO}_{3}$} & 5 & $17.7^{\mathrm{h}}$ \\
\hline & 10 & $3.0^{\mathrm{j}}$ \\
\hline & 15 & $1.0 \mathrm{j}$ \\
\hline & 20 & $0.3^{\mathrm{j}}$ \\
\hline \multirow{4}{*}{$\mathrm{KH}_{2} \mathrm{PO}_{4}$} & 5 & $93.3^{\text {ba }}$ \\
\hline & 10 & $90.0^{\mathrm{bc}}$ \\
\hline & 15 & $86.7^{\mathrm{dc}}$ \\
\hline & 20 & $81.7^{\mathrm{de}}$ \\
\hline \multirow{4}{*}{$\mathrm{K}_{2} \mathrm{HPO}_{4}$} & 5 & $88.0^{\mathrm{bc}}$ \\
\hline & 10 & $63.3^{\mathrm{f}}$ \\
\hline & 15 & $11.0^{\mathrm{i}}$ \\
\hline & 20 & $2.3^{\mathrm{j}}$ \\
\hline \multirow{4}{*}{$\mathrm{K} 2 \mathrm{CO}_{3}$} & 5 & $0.3^{\mathrm{j}}$ \\
\hline & 10 & $0.0^{\mathrm{j}}$ \\
\hline & 15 & $0.0^{\mathrm{j}}$ \\
\hline & 20 & $0.0^{\mathrm{j}}$ \\
\hline Control & 0 & $97.3^{\mathrm{a}}$ \\
\hline LSD (5\%) & & 6.21 \\
\hline $\mathrm{CV}(\%)$ & & 9.58 \\
\hline
\end{tabular}

Means within a column followed by the same letter are not significantly different, CV=Coefficient of Variation,LSD = LeastSignificance Difference

The effects of inorganic salt foliar sprays on wheat stem rust

There was a significant $(\mathrm{P}<0.05)$ difference among inorganic salts and their concentrations in reducing pustule length and pustule number of Pgton the susceptible host 'McNair' (Table 02). The lowest number of pustules and pustule lengths were recorded from plants treated with potassium carbonate and potassium bicarbonate (Figure 02). Plants treated with potassium carbonateat concentrations of $10-20 \mathrm{gl}^{-1}$ had the lowest mean pustule count of 5.3-8.0 followed by potassium bicarbonate and sodium bicarbonate at concentration of $10-20 \mathrm{gl}^{-1}$ with mean pustule counts of $6.7-8.5$ and $7.7-10$ per single leaf, respectively. The highest number of pustules and pustule lengths were recorded from plants treated with potassium dihydrogen phosphate and sodium chloride at $5 \mathrm{gl}^{-1}$, respectively. 

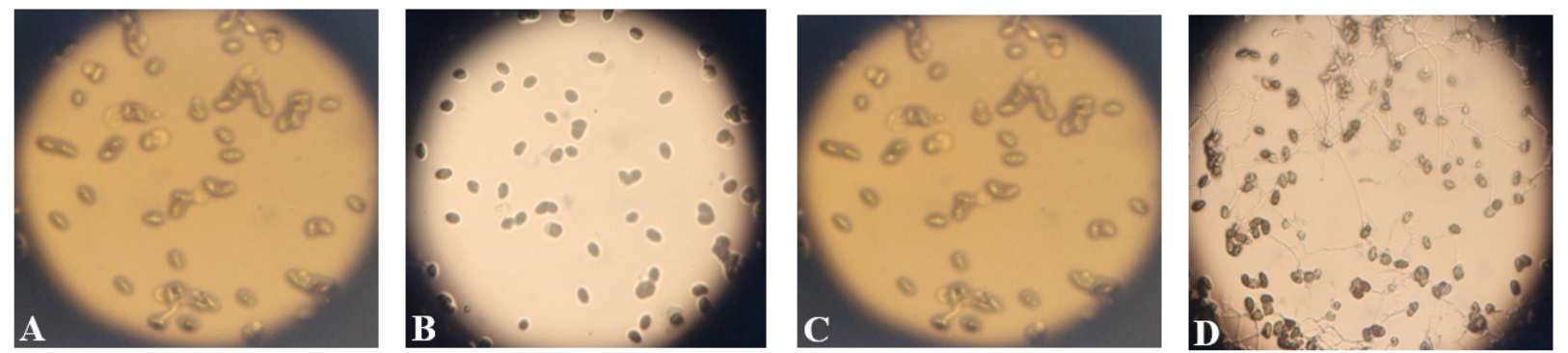

Figure 01: Inhibitory effect of inorganic salts on the germination of Pgt uredospores under invitro condition. A) $\mathrm{KHCO}_{3}$ at $\left.15 \mathrm{gl}^{-1} \mathrm{~B}\right) \mathrm{K}_{2} \mathrm{CO}_{3}$ at $15 \mathrm{gl}^{-1} \mathrm{C}$ ) $\mathrm{NaHCO}_{3}$ at $15 \mathrm{gl}^{-1} \mathrm{D}$ ) Water (control)

Table 02: The effect of inorganic salts on the infection of Pgtunder greenhouse condition

\begin{tabular}{|c|c|c|c|}
\hline Inorganic salt & Concentration $\left(\mathrm{gl}^{-1}\right)$ & Number of pustule/leaf & Pustule length (mm) \\
\hline \multirow{4}{*}{$\mathrm{NaHCO}_{3}$} & 5 & $10.0^{\mathrm{mn}}$ & $2.7^{\text {ba }}$ \\
\hline & 10 & $9.0^{\mathrm{pno}}$ & $2.0^{\text {de }}$ \\
\hline & 15 & $8.3^{\mathrm{pqo}}$ & $1.3^{\mathrm{ghhi}}$ \\
\hline & 20 & $7.7^{\mathrm{pqr}}$ & $1.1^{\mathrm{ji}}$ \\
\hline \multirow{4}{*}{$\mathrm{NH}_{4} \mathrm{HCO}_{3}$} & 5 & $12.0^{\mathrm{kjj}}$ & $2.2^{\mathrm{dc}}$ \\
\hline & 10 & $11.5^{\mathrm{kl}}$ & $1.7^{\mathrm{gef}}$ \\
\hline & 15 & $10.7^{\mathrm{ml}}$ & $1.2^{\mathrm{jhi}}$ \\
\hline & 20 & $9.7^{\mathrm{mno}}$ & $1.0^{\mathrm{j}}$ \\
\hline \multirow{4}{*}{$\mathrm{KCl}$} & 5 & $14.5^{\text {ghefd }}$ & $2.7^{\text {ba }}$ \\
\hline & 10 & $13.8^{\mathrm{ghi}}$ & $2.6^{\mathrm{b}}$ \\
\hline & 15 & $13.2^{\mathrm{hij}}$ & $2.0^{\text {de }}$ \\
\hline & 20 & $12.5^{\mathrm{kij}}$ & $1.3^{\mathrm{ghi}}$ \\
\hline \multirow{4}{*}{$\mathrm{NaCl}$} & 5 & $15.5^{\mathrm{cebd}}$ & $2.8^{\mathrm{ba}}$ \\
\hline & 10 & $14.5^{\text {ghefd }}$ & $2.5^{\mathrm{bc}}$ \\
\hline & 15 & $15.0^{\mathrm{ghf}}$ & $2.0^{\text {de }}$ \\
\hline & 20 & $13.3^{\mathrm{hij}}$ & $1.7^{\mathrm{gef}}$ \\
\hline \multirow{4}{*}{$\mathrm{KHCO}_{3}$} & 5 & $8.5^{\mathrm{po}}$ & $2.0^{\mathrm{de}}$ \\
\hline & 10 & $7.7^{\mathrm{pqr}}$ & $1.4^{\mathrm{ghi}}$ \\
\hline & 15 & $7.0^{\mathrm{sqr}}$ & $1.0^{\mathrm{j}}$ \\
\hline & 20 & $6.7^{\mathrm{str}}$ & $1.0^{\mathrm{j}}$ \\
\hline \multirow{4}{*}{$\mathrm{KH}_{2} \mathrm{PO}_{4}$} & 5 & $16.8^{\mathrm{b}}$ & $2.0^{\text {de }}$ \\
\hline & 10 & $16.0^{\mathrm{cb}}$ & $2.0^{\mathrm{de}}$ \\
\hline & 15 & $15.3^{\text {cefd }}$ & $1.4^{\mathrm{ghi}}$ \\
\hline & 20 & $14.5^{\text {ghefd }}$ & $1.4^{\mathrm{ghi}}$ \\
\hline \multirow{4}{*}{$\mathrm{K}_{2} \mathrm{HPO}_{4}$} & 5 & $15.7^{\mathrm{cbd}}$ & $2.0^{\mathrm{de}}$ \\
\hline & 10 & $14.8^{\text {gcefd }}$ & $2.0^{\text {de }}$ \\
\hline & 15 & $14.2^{\text {ghef }}$ & $2.0^{\mathrm{de}}$ \\
\hline & 20 & $13.8^{\mathrm{ghi}}$ & $1.8^{\mathrm{def}}$ \\
\hline \multirow{4}{*}{$\mathrm{K}_{2} \mathrm{CO}_{3}$} & 5 & $8.0^{\mathrm{pqr}}$ & $1.5^{\mathrm{ghf}}$ \\
\hline & 10 & $7.0^{\mathrm{sqr}}$ & $1.0^{\mathrm{j}}$ \\
\hline & 15 & $6.2^{\mathrm{st}}$ & $1.0^{\mathrm{j}}$ \\
\hline & 20 & $5.3^{\mathrm{t}}$ & $1.0^{\mathrm{j}}$ \\
\hline \multirow[t]{3}{*}{ Control } & 0 & $18.3^{\mathrm{a}}$ & $3.0^{\mathrm{a}}$ \\
\hline & $(5 \%)$ & 1.37 & 0.34 \\
\hline & $(\%)$ & 7.17 & 11.82 \\
\hline
\end{tabular}

Means within a column followed by the same letter are not significantly different, CV = Coefficient of Variation, LSD $=$ Least Significance Difference 

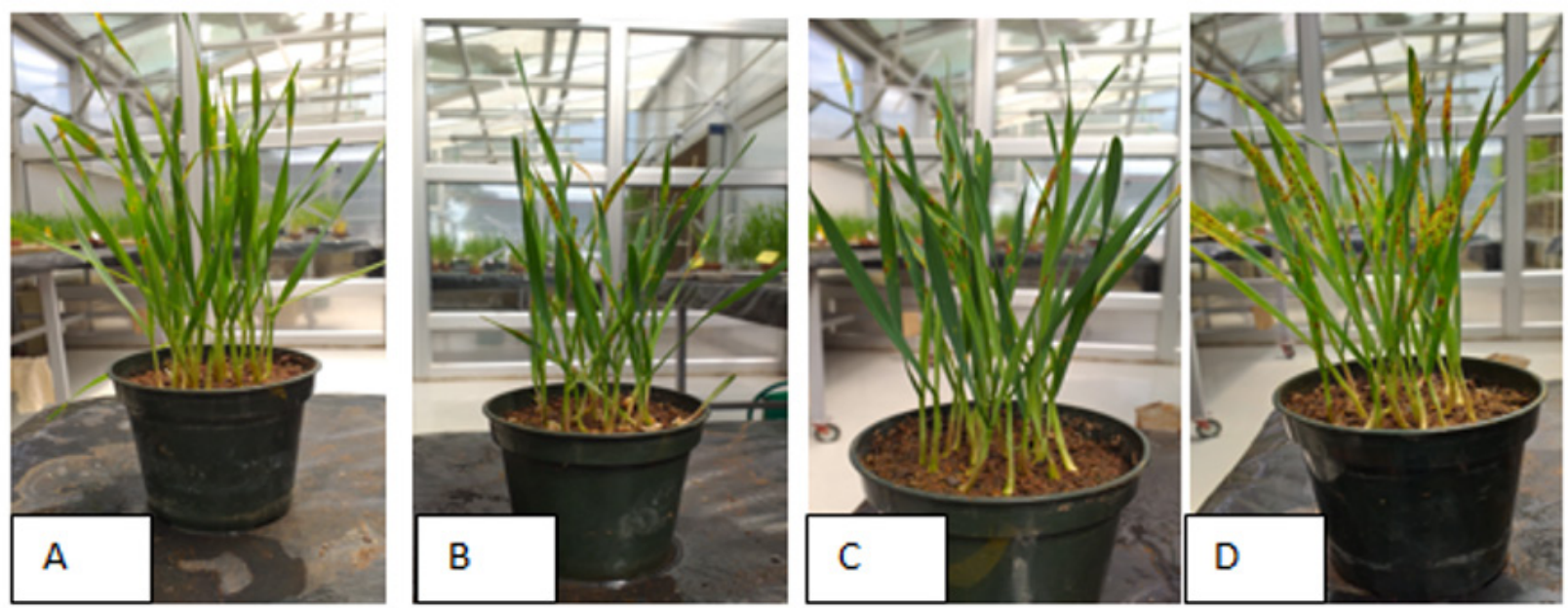

Figure 02: $\quad$ Effect of inorganic salts on the spore development of $P g t$ under greenhouse condition. A) $\mathrm{K}_{2} \mathrm{CO}_{3}$ at $\left.15 \mathrm{gl}^{-1} \mathrm{~B}\right) \mathrm{NaHCO}_{3}$ at $15 \mathrm{gl}^{-1} \mathrm{C}$ ) $\mathrm{KHCO}_{3}$ at $15 \mathrm{gl}^{-1} \mathrm{D}$ ) Water (Control)

A previous study by Caldwell et al., (2013) showed that the use of potassium bicarbonate resulted in good control of black rot and Phomopsison grapes and leaf spot on strawberry. Powdery mildew, caused by Sphacerothecapannosavar. rosae, and black spot, caused by Diplocarponrosae, were significantly controlled by weekly sprays of sodium bicarbonate on Rosa species (Horst et al., 1992). Arslan et al., (2006) showed that potassium bicarbonate, sodium bicarbonate and ammonium bicarbonate, concentrations ranging from $0.47-12 \mathrm{~g} \quad 1^{-1}$ completely inhibited spore germination and germ tube elongation of the uredospores of bean rust (Uromycesappendiculatus) and wheat leaf rust (Pucciniatriticina) under in-vitro and pot experiments in controlled environments indicating that spray applications of potassium bicarbonate $\left(6 \mathrm{~g} \mathrm{l}^{-1}\right)$, sodium bicarbonate (10.1 $\left.\mathrm{g} \mathrm{l}^{-1}\right)$ and ammonium bicarbonate (9.4 $\left.\mathrm{g} \mathrm{1}^{-1}\right)$ to 10-day-old wheat plants of the highly susceptible Gonen cultivar reduced the number of $P$. triticina pustules on the leaves by 82,92 and $90 \%$, respectively, relative to controls. In the present study potassium chloride was not effective in controlling wheat stem rust disease but Mann et al., (2004) showed that potassium chloride was effective in reducing the severity of septoria leaf blotch on winter wheat. Prabhu et al., (2007) noted that the effect of potassium on disease can be classified as "increased", "decreased" and having "no effect" or "variable effect". The variable effects of potassium on disease could be affected by the amount and source of the element, plant and pathogen species.

The present study showed that potassium carbonate and potassium bicarbonate as the best inorganic salts in controlling stem rust development on the susceptible wheat cultivar 'McNair' by suppressing the germination of uredospores and limiting the development of pustules. Various authors have proposed different mechanisms in which potassium improves the resistance of plants against pathogens. For example, Feng \& Zeng (2006) and Machinandiarena et al., (2012) stated that potassium increases the resistance of plants to stresses and supports the natural defense of plants against pathogens. These have been linked to processes such as $\mathrm{pH}$ elevation on the leaf surface (Ziv and Zitter, 1992), and collapse of fungal cell walls due to $\mathrm{K}^{+}$imbalance or dehydration of fungal spores (HDC, 2005).

It is also important to mention that ammonium bicarbonate, potassium carbonate and potassium bicarbonate had a slight burning effect on the leaf margins of wheat at the highest concentration $\left(20 \mathrm{gl}^{-1}\right)$. This was an indicator that at higher concentrations inorganic salts may have phototoxic effects on wheat leaves. The present observation concurs with previous studies by various authors (Ilhan et al., 2006; Karabulut et al., 2005) about the phytotoxic effects of inorganic salts on several plant species. Hence, there is a need to be cautious 
when recommending inorganic salts for the management of plant diseases.

\section{CONCLUSION}

Stem rust caused by Pucciniagraminisf. sp. triticit $(P g t)$ is a serious wheat disease that causes high yield reduction in wheat. Their emergence of a new virulent race in eastern African regions and the subsequent detection of its variants have rendered important commercial varieties become susceptible. The use of fungicide is not safe to the environment and applicators. Hence, inorganic salts may overcome the challenges associated with fungicides. The present study showed that germination of uredospores of $P g t$ was strongly affected by application of potassium carbonate and potassium bicarbonate, in-vitro. Potassium carbonate completely inhibited $(100 \%)$ the germination of the fungal spores at $10-20 \mathrm{gl}^{-1}$ concentrations, whereas potassium bicarbonate reduced germination by $99 \%$ at $15 \mathrm{gl}^{-1}$ and $100 \%$ at $20 \mathrm{gl}^{-1}$ concentrations. Similarly, the number of pustules and pustule lengths were significantly reduced by these two inorganic salts when tested in-vivo, in a greenhouse environment. This is an indication that the two inorganic salts, potassium carbonate and potassium bicarbonate, have the potential to manage wheat stem rust. However, further investigations on the rate, frequency and time of application under field environment is required before making definitive conclusions.

\section{Data Availability Statement}

The datasets generated and analyzed during the current study are not publicly available. They are available from the corresponding author on reasonable request.

\section{Conflict of Interests}

The authors had not declared any conflict of interests.

\section{ACKNOWLEDGMENTS}

The authors are thankful to Ambo Agricultural Research Center wheat rust research team for technical support and for MOE and Debre Tabor University for their financial support.

\section{REFERENCES}

Arslan U, Ilhan K, Karabulut O.A. (2006). Evaluation of food additives and low-toxicity compounds for the control of bean rust and wheat leaf rust. J. Phytopathol.154:534-541.

Avis T.J. (2007).Antifungal compounds that target fungal membranes: applications in plant disease control. Can. Plant Pathol. 29: 323-329.

Bechere E, Kebede H, Belay G. (2000). Durum wheat in Ethiopia: An old crop in an ancient land. Institute of Biodiversity Conservation and Research (IBCR), p 68.

BombelliE.C., Wright E.R. (2006). Tomato fruit quality conservation during post-harvest by application of potassium bicarbonate and its effect on Botrytis cinerea. Cien. Inv. Agr. 33(3): 167-172.

Caldwell B, Sideman E, Seaman A, Shelton A, Smart C. (2013). Resource guide for organic insect and disease management, 2nd edition, New York State Agricultural Experiment Station.

CSA(Central Statistics Agency),(2018). Report on Area and production of Major Crops. The Federal Democratic Republic of Ethiopia; Central Statistics Agency Agricultural Sample Survey for 2017/2018. Addis Ababa, Ethiopia. Statistical Bulletin 586:1-57.

Droby S, Wisniewski M.E., Ghaouth A, Wilson C. (2003). Influence of food additives on the control of postharvest rots of apple and peach and efficacy of the yeast-based biocontrol product Aspire. Postharvest Biol.Technol. 27: 127-135. 
Fallik E, Grinberg S, Ziv O. (1997).Potassium bicarbonate reducespostharvest decay development on bell pepper fruits. J.Hort.Sci.72:35-41.

FAO (Food and Agriculture Organization), (2015). Food and Agriculture Organization of the United Nations, Rome, 2015

Feng W, Zheng X. (2006). Control of Alternaria alternate by cassia oil in combination with potassium chloride or sodium chloride. J. Appl. Microbiol.101: 1317-1322.

HDC (Horticultural Development Company),(2005). Use of Potassium Hydrogen Carbonate for Powdery Mildew Control. Final Report on HDC Project CP 48. HDC, East Malling, UK, p30.

Horst R.K., Kawamoto S.O., Porter L.L. (1992). Effect of sodium bicarbonate and oils on the control of powdery mildew and black spot of roses. Plant Dis. 76: 247-251.

IlhanK, ArslanU, Karabulut O.A. (2006). The effect of sodium bicarbonate alone or in combination with a reduced dose of tebuconazole on the control of apple scab. Crop Protect.25: 963 - 967.

KarabulutO.A., ArslanU, IlhanK, Kuruoglu G.(2005). Integrated control of postharvest disease of sweet cherry with yeast antagonists and sodium bicarbonate applications within a hydrocooler. Postharvest Biol. Technol.37: 135 - 41.

Kibria G, YousufHaroon A.K., Nugegoda D, Rose G.(2010). Climate change and chemicals. Environmental and biological aspects. New India Publishing Agency, PitamPura, New Delhi.

Latifa A, Idriss T, Hassan B, Amine S.M., Hassane B, Abdellah A.B.A. (2011). Effects of organic acids and salts on the development of Penicilliumitalicum: the causal agent of citrus blue mold. Plant Pathol J. 10: 99-107.

Leonard K.J., Szabo L.J.(2005). Stem rust of small grains and grasses caused by Pucciniagraminis. Molecular Plant Pathol.6: 99-111.

Machinandiarena M.F., Lobato M.C., Feldman M.L., Daleo G.R., Andreu A.B.(2012). Potassium phosphite primes defense responses in potato against Phytophthorainfestans. J. Plant Physiolo. 169: 1417-1424.

Mann R.L., KettlewellP.S., Jenkinson P.(2004). Effect of foliar applied potassium chloride on septoria leaf blotch of winter wheat. Plant Pathol.53: 653 -659.

Minot N, Warner J, Lemma S, Kassa L, Gashaw A, Rashid S.(2015). The Wheat Supply Chain in Ethiopia: Patterns, Trends, and Policy Options. International Food Policy Research Institute (IFPRI) Washington, DC.

Palou L, Smilanick J.L., Usall J, Viñas I.(2001). Control of postharvest blue and green molds of oranges by hot water, sodium carbonate, and sodium bicarbonate. Plant Dis. 85: 371-376.

Prabhu A.S., Fageria N.K., Huber D.M. (2007). Potassium Nutrition and Plant Diseases. In Mineral Nutrition and Plant Disease; Datnoff L.E., Elmer W.H., Huber D.M. Eds.; American Phytopathological Society: Saint Paul, MN, USA, 57-78.

Reuveni M, Agapov V. Reuveni R.(1995). Induced systemic protection to powdery mildew in cucumber by phosphate and potassium fertilizers: effects of inoculums concentration and post-inoculation treatment. Can. J.Plant Pathol. 17: 247-251 
Roelfs A.P. (1985). The cereal rusts, Vol. II: Diseases, distribution, epidemiology and control pp. 403-434. In: Orlando (FL): Academic Press. Chapter 13, Epidemiology in North America.

SAS(Statistical Analysis System), (2003). Institute Inc., SAS/STAT Guide for Personal Computers, SAS Institute Inc., Cary, North Carolina, USA, (version 9.1.3 edition).

Turkkan M, Ozcan M, Erper I.(2017). Antifungal effect of carbonate and bicarbonate salts against Botrytis cinerea, the casual agent of grey mould of kiwifruit. AkademikZiraatDergisi. 6 (2): 107-114

Youssef K, Ligorio A, Sanzani S.M., NigroF, Ippolito A.(2012). Control of storage diseases of citrus by pre- and postharvest application of salts. Postharvest Biol Technol. 72: 57-63.

Zegeye T, Taye G, Tanner D, Verkuij1 H, Agidie A,Mwangi W.(2001). Adoption of improved bread wheat varieties and inorganic fertilizer by small-scale farmers in yelmanaDensaand Farta districts of Northwestern Ethiopia. EARO and CIMMYT. Mexico city, Mexico.

Ziv O,Zitter T.A. (1992). Effects of bicarbonates and film-forming polymers on cucurbit foliar diseases. Plant Dis.p76. 